\title{
Joint effects of word association and approximation to English'
}

ROY LACHMAN, JOSEPH S. DUMAS AND LAWRENCE T. GUZY

STATE UNIVERSITY OF NEW YORK AT BUFFALO

Four lexical training lists were administered in a 2 by 2 factorial experiment. The lists were constructed to reflect two levels of approximation to English (a nonsyntactical word order and an English paragraph) and two levels of word association. A significant interaction was obtained for each of several retention measures employed. The data support the view that high frequency associates, when incorporated into natural language discourse, load the passage with high frequency phrases (cliches) and make a high approximation to English still higher.

Association levels, according to a recent study, influence the recall of words presented in connective discourse (Rosenberg, 1966). The study followed logically from work demonstrating the effects on recall of various extra-experimental relationships among words. Deese (1959), for example, demonstrated that recall covaries with the inter-item associative strength of randomly ordered words. Subsequently, Garskoff, Houston, \& Ehrlich (1963) found that two distinct aspects of associative relatedness independently influence the recall of word pairs.

Rosenberg reasoned that associations between words in connective discourse (conventionally syntactic English narrative) should also facilitate various measures of recall. Accordingly, he prepared two English paragraphs as training material to test this hypothesis. A set of words consisting of "stimulus" words and a maximum of five strong associations for each stimulus word was selected from normative data. Each word was worked into a high associative strength (HA) paragraph. In a low associative strength (LA) paragraph, the so called stimulus words remained but the previous "response" words were replaced by words of approximately zero association to each stimulus word. All other words as well as phrase structures and sentence frames were identical for the two sets of training materials. Each paragraph was presented once in what is best described as a two independent group design. The report included comparisons between the HA and LA paragraphs for several types of recall data including mean number of stimulus words, primary response words, and $\mathbf{S}-\mathbf{R}$ pairs recalled. In all cases significantly more words were recalled from the HA paragraph. Rosenberg (1966, p. 54) concluded, "that associative habit plays an important role in the recall of connective discourse."

An examination of the training materials suggested that the two paragraphs employed by Rosenberg differed not only in associative factors but also with respect to degree of contextual constraints. Certain sequences of words in the HA paragraph may have a higher probability of occurring in the natural language than do corresponding sequences in the LA paragraph. For example, the following are phrases in the HA paragraph, there had been much to eat the sight of all that food

The corresponding LA phrases are,

there had been much to taste

the sight of all that dinner
It is possible that many of the phrases in the HA paragraph such as (1) and (b) occur more frequently in spoken or printed English discourse than do the correlated LA phrases; a number of judges all agreed with this interpretation after examining the paragraphs.

The present experiment is a replication of the HA and LA conditions of Rosenberg's study with the addition of two control conditions. Modified HA and LA lists were prepared that effectively destroyed all syntactical structure, phrases and sentences. Context words preceding and following the various stimulus and response words were randomly ordered in the control lists, but the number of context words between each stimulus and response word was invariant for all four lists.

Method

Design. A 2 by 2 factorial design was employed involving training lists at high (HAE) or low (LAE) approximation to English (paragraph or nonsyntactical word order), and containing words highly associated (HA) or of very low association (LA).

Subjects. The Ss, 80 introductory psychology students at the State University of New York at Buffalo, were fulfilling a course requirement.

Verbal material. Four 149 word training lists were employed. Each contained the same 16 stimulus words in identical serial locations, and 26 response words at the same serial position in each list. In the HA lists, 16 of the response words were primary associates of the stimulus words and 10 were secondary associates (Palermo \& Jenkins, 1964). Response words in the LA lists were all low associates. The two sets of connective discourse, lists HAE-HA and HAE-LA, were taken directly from Rosenberg (1966). Context words, all words other than stimulus and response words, were randomly assigned to context locations in lists LAE-HA and LAE-LA. The lists were recorded in near monotone on magnetic tape.

Procedure. The procedure was essentially the same as that of Rosenberg (1966). Ss were randomly assigned to one of the four training conditions, and were run in a 
Table 1. Mean Words Correct

\begin{tabular}{|c|c|c|c|c|c|c|c|c|c|}
\hline Association & & $\mathrm{HA}$ & LA & $\mathrm{HA}$ & LA & $\mathrm{HA}$ & LA & $\mathrm{HA}$ & LA \\
\hline Typ & & "Stim & $\begin{array}{l}\text { olus" } \\
\text { ds }\end{array}$ & $\begin{array}{l}\text { Prin } \\
\text { "resp } \\
\text { wo }\end{array}$ & $\begin{array}{l}\text { ury } \\
\text { nse", } \\
\text { ds }\end{array}$ & $\begin{array}{r}\text { Al } \\
\text { "respo } \\
\text { wor }\end{array}$ & se" & $\begin{array}{r}\text { "Sti } \\
\text { resp } \\
p\end{array}$ & $\begin{array}{l}\text { lus } \\
\text { se" } \\
\text { s }\end{array}$ \\
\hline Approximo & HAE & 7.85 & 5.75 & 7.30 & 4. 10 & 11.15 & 6.25 & 4.45 & 35 \\
\hline $\begin{array}{l}\text { tion to } \\
\text { English }\end{array}$ & LAE & 3.95 & 4.4 & 4.75 & 3.60 & 7.15 & 5.25 & 2.20 & 95 \\
\hline Rosenberg & AAE & 9.26 & 7.22 & 8.07 & 4.78 & 13.00 & 7.85 & 6.15 & 3.04 \\
\hline
\end{tabular}

classroom in groups of 20 . The recall instructions administered encouraged guessing. Presentation time was approximately $63 \mathrm{sec}$. for each list. Four sec. after a single presentation, $7 \mathrm{~min}$. was allowed for a written recall test.

\section{Results and Discussion}

A word was scored correct only if reproduced exactly. Number correct was tallied for stimulus words, primary response words, all response words, and stimulusprimary-response pairs. The means for each measure and comparable data from Rosenberg (1966) are presented in Table 1. F ratios for each measure are presented in Table 2. Relative magnitudes of recall obtained by Rosenberg have been reproduced in the present study although absolute recall scores are consistently less.

A significant interaction was obtained for every measure employed. The magnitude of associative effects on

Table 2. F Ratios for Words Correct

\begin{tabular}{|c|c|c|c|c|c|}
\hline \multirow{3}{*}{ Type of words } & \multicolumn{3}{|c|}{$\begin{array}{c}\text { Primary } \\
\text { "Stimulus" "response" }\end{array}$} & $\begin{array}{l}\text { All } \\
\text { response". }\end{array}$ & $\begin{array}{l}\text { "Stimulus- } \\
\text { response" }\end{array}$ \\
\hline & & words & words & words & pairs \\
\hline & $d f$ & $\mathrm{~F}$ & $\mathrm{~F}$ & $\mathrm{~F}$ & $\mathrm{~F}$ \\
\hline \multicolumn{6}{|l|}{ Approximation to } \\
\hline English & 1 & $30.30 * * *$ & $11.17 * *$ & $15.98^{* * *}$ & $13.50 * * *$ \\
\hline Association level & 1 & 3.04 & $22.72 * * *$ & $29.55^{* * *}$ & $10.62^{* *}$ \\
\hline Interaction & 1 & $7.27 * *$ & $5.04^{*}$ & $5.75^{*}$ & $6.58 *$ \\
\hline Residual (mean square) & 76 & $(4.47)$ & $(4.17)$ & $(7.82)$ & $(2.60)$ \\
\hline
\end{tabular}

retention obviously depends upon the syntax of the learning materials. Relative superiority of high frequency associative material to low frequency associations is considerably reduced when the training list is nonsyntactical. These results may be rendered intelligible according to one view by the stimulus word data. Significantly more stimulus words were recalled from the HA list than from the LA list selectively for the connective discourse; the corresponding differences were in the opposite direction for the LAE lists. It would seem, therefore, that a HAE passage precipitates the recall of more stimulus words in a high associative context. Enhanced recall of these stimulus words generates greater recall of the $\mathrm{HA}$ response words. The result is maximum recall for the $\mathrm{HAE}-\mathrm{HA}$ condition. One difficulty with this interpretation is that it fails to explicate the mechanism by which the recall for stimulus words in a high frequency associative environment is enhanced by syntactic discourse. If bidirectional associative effects are now suggested to account for the stimulus word data, then the reasoning involved becomes completely circular. Perhaps the inclusion of high frequency associates in connective discourse provides a closer approximation to the most common verbal environment of the natural language. High frequency associates incorporated into a paragraph, in short, may load the passage with the most common cliches of the language and make a high approximation to English still higher.

\section{References}

Deese, J. Influence of inter-item associative strength upon immediate free recall. Psychol. Rep., 1959, 5, 305-312.

Garskoff, B. E., Houston, J. P., \& Erlich, -N. J. Inter- and Intrahierarchical verbal relatedness. J. verbal Learn. verbal Behav., 1963, 2, 229-233.

Palermo, D. S., \& Jenkins, J. J. Word association norms: Grade school through college. Minneapolis: University of Minnesota Press, 1964.

Rosenberg, S. Associative factors in the recall of connected discourse. Psychon. Sci., 1966, 4, 53-54.

Note

1. Supported by NIH MH-10764. 